\title{
Some reflections on the conference background paper: 'Improving Local Government: the Commonwealth Vision'
}

\section{Commonwealth Journal of Local Governance \\ Special Issue March 2010: \\ Commonwealth Local Government Conference \\ Freeport, Bahamas, May 2009 \\ http:/lepress.lib.uts.edu.au/ojs/index.php/cjlg}

\section{Joseph Stern}

International development consultant, Canada

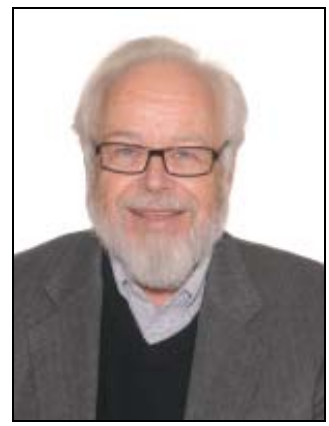

Even before considering its content, one has to admire the confidence of Dr. Philip Amis to undertake the preparation of a paper titled: Improving Local Government: the Commonwealth Vision. Dr. Amis, head of the International Development Department at the University of Birmingham and a trusted friend of the Commonwealth Local Government Forum, would have understood the challenges of this assignment. There is no commonly accepted definition of 'local government' and practitioners have agreed that replicable models or templates for local government improvement are hard to find. Moreover, the Commonwealth is not much easier to define than local government and has been reticent historically to translate its various 'vision' statements into actionable plans. $^{1}$

\footnotetext{
1 This reticence reflects the ethos of the Commonwealth as a familial association promoting dialogue and fostering consensus. The aversion to judgments and actions that characterize deficiencies in some member states as failures in governance is based on a desire to preserve that ethos. Nevertheless, the Commonwealth has not backed away from stating, promoting and protecting its core values. The 1991 Harare Declaration and the subsequent adoption of the Millbrook Action Program to implement the Declaration clearly demonstrate this resolve.
} 
The paper (http://www.clgc2009.org/index.cfm/pageid/305/Background+paper) itself vindicates the confidence of the author. The research and narrative presented is a tour de force of the field of local government and the series of progressive responses by the Commonwealth. It lays out the case for focusing on local government, noting inter alia the contribution of Professor Jeffrey Sachs in his paper to the 2007 CLGF Conference, identifying the link between effective local government and the achievement of the Millennium Development Goals. The three substantive sections of Dr Amis' Improving Local Government - Financing Local Government; Democracy and Accountability; and Improving Performance - all draw upon case studies from the Commonwealth where different approaches have achieved positive outcomes. The paper concludes with an agenda for the 2009 Bahamas Conference. The outcome of the Conference, expressed in the Freeport Declaration, uses the framework of issues for discussion and implementation presented by $\operatorname{Dr}$ Amis, and draws on both his analysis and the conclusions of the Research Colloquium where the background paper was discussed in the two days before the Conference formally convened. Thus the paper clearly served the purpose for which it was drafted.

This short commentary will not attempt to summarize the content of the paper. Dr. Amis' study, in its entirety, is relatively concise and highly readable and I commend it to the readers of this journal who are not already familiar with it. I particularly recommend the report to researchers and development practitioners for despite the title, the work is much more a practitioner's guide than it is a vision statement. Indeed, while the paper invokes the antecedent statements of principles that led to the Freeport conference, a Commonwealth vision for local government remains elusive. This is an observation, not a criticism of the paper. In the field of development, particularly in relation to governance and democratic reform, the main problem is not the absence of vision or policy or even research for that matter. It is the inability to transform the thinking and the analysis to action. The theme Amis weaves through his paper is the importance of finding out what works and how to make it sustainable.

As noted earlier, the attempt to identify what works is constrained by an absence of common nomenclature for local government and thus a shared appreciation of the problems that need to be solved. In addition to a lack of consensus on exactly what is meant by decentralization or local government, the very concept is highly variable to questions of scale: the size of states themselves and the size of units of local 
government. Amis presents the astonishing statistic that more than half the world's population now lives in urban areas, many or perhaps most of whom live in mega-cities that are more populous than the majority of Commonwealth countries (two-thirds of which have populations under 1.5 million). In addition to the variable of size, there are multiple models reflecting different constitutional or statutory provisions, differences on the spectrum of power sharing, ranging from greater citizen participation at the local level through decentralization of services to devolution of authority and resources to local democratic organs, as well as differences in the heterogeneity of the populations, their stage of development, and their state of fragility.

The way Amis deals with this difficulty is to take an approach that situates his analysis and prescriptions at a high enough level of aggregation to be as inclusive as possible. His section on the local government context thus focuses on issues such as: rapid urbanization and urban poverty; the importance of local government in achieving the Millennium Development Goals; the implementation of energy efficiency and mitigation approaches to climate change; and local government and the global economic crisis. He is in good company. Since the mid 1980s the World Bank has viewed the transfer of power from the national to sub-national levels of government as an essential strategy for economic development and poverty reduction. This approach has been embraced by other institutions including the Organization of American States (OAS) and the InterAmerican Development Bank (IDB), which ranks decentralization and effective local governance as one of the five essential attributes of good governance upon which its funding decisions are based. The Secretary-General of CARICOM, in his address to the Freeport conference, acknowledged that the strengthening of local government is inextricably linked to sustainable development and regional integration in the Caribbean.

If there is something missing in the vision implicit in this approach, it is the inspiration of the Harare Declaration and its recognition of governance and basic human rights as the unifying commitment of Commonwealth states. What distinguishes local government reform from macro-economic strategies as an engine of economic development, is that the latter (by its nature) reflects a growth-based approach, and the former (also by its nature), opens the door to a rights-based approach. We know from the era of mega infrastructure projects and the subsequent efforts under structural adjustment programs that growth-based approaches often do not reach the people most desperately in need of the benefits of development. A rights-based approach promotes human development by 
striving to respond to the rights of every citizen to good governance and quality services, to essential infrastructure, to social stability, to a clean and safe environment, to potable water and health care, and to economic opportunity. This is the promise of local government reform.

As noted earlier, previous evaluations as well as the Amis report all conclude that one size does not fit all, and that it is more important to discover what succeeds in each particular situation than to look for some illusive template that can be broadly replicated. In its most recent evaluation of its \$22 billion portfolio of decentralization programs, the World Bank noted that a consensus on what needs to been done in any particular situation is a high predictor of program results. The consensus the World Bank is referring to is not a consensus among states or donor consortia on what needs to be done, but importantly a consensus within states by all the stakeholders at the various levels of government, in the private sector, and in civil society. This consensus-based polity is missing in many Commonwealth states where a well-established tradition of winnertake-all is difficult to dislodge. Until this approach is broadly embraced, the relatively anodyne analyses and technical prescriptions contained in the background paper for the Freeport conference will not be capable of achieving the results that are so manifestly needed.

The vision for improving local government that should animate the Commonwealth is to encourage its member states to act upon their local as well as global responsibilities to protect and enhance the health and well-being of humans and ecosystems. In so doing, states must be committed to see this vision reflected in the way they govern, the way they communicate, the way they allocate resources, and the way they respond to the needs of their most vulnerable citizens. For example, if this vision were more evident in the background paper, there might have been greater attention to the impact of local services on women who are particularly affected by access to potable water, primary health care, education, sanitation, local transportation, and recreational facilities. All of these are primarily matters best dealt with at the level of local government. To make governments respond to these needs, the argument must be framed in the context of respect for the rights of women and not just in the language of efficient service delivery. More focus on a rights-based approach might have also resulted in more attention to the special circumstances of indigenous peoples. The world's 200 million indigenous peoples are often in the most underprivileged and underdeveloped position in society, facing poverty, 
human rights abuses and social exclusion. Aboriginal self-government is an important issue in a number of Commonwealth countries including my own country of Canada. There should be room in the Commonwealth vision for local government that encompasses indigenous peoples.

The path of the Commonwealth's embrace of the issue of local government is one marked by incremental but steady progress. Both the report prepared by Professor Amis and the Freeport Declaration follow that trajectory and portend continuing progress. The penultimate section of the background paper - Towards a Way Forward - lays out some of the steps necessary to sustain that progress. The section would have been strengthened by highlighting the importance of civic education and the need for more dialogue within countries to build consensus on the role of local government.

Changes in local government will only occur when national governments have the will to act. For that to happen, people need to be made aware that effective local government gives them an opportunity to take charge of many of those aspects of their lives that most concern them on a daily basis. The essential message that needs communication at the local level is that local government empowers ordinary citizens to bring about that change. When meaningful local government reform occurs in reluctant states, it is more likely to be a result of a groundswell of demand from the grassroots than from an epiphany in the councils of national governments. 